\title{
VIKTOR E. FRANKL UND DER HOLOCAUST
}

\author{
Risto Nurmela \\ Pargas
}

Der österreichische Psychotherapeut Viktor E. Frankl wurde im Jahre I9os in einer jüdischen Familie in Wien geboren. Die Familie wohnte im zweiten Bezirk, der 1910 von allen Bezirken den höchsten Anteil an Juden hatte, nämlich 33,95 Prozent bzw. 56.779 Personen. Insgesamt lebten damals in Wien 175.000 Juden, die aber beinahe alle unter der letzten Hälfte des 19. Jahrhunderts dorthin gezogen waren. ${ }^{1}$ Frankl lebte mit seinen Eltern bis er 1942 ins Konzentrationslager Theresienstadt deportiert wurde. Nach der Befreiung kehrte er nach Wien zurück, und ist dort 1997 verstorben.

Im Jahre 1942 wurden Frankl, seine Frau Tilly und seine Eltern nach Theresienstadt deportiert. Er hatte im Dezember 194I geheiratet, und noch vor der Deportation war das Ehepaar gezwungen, ihr erstes Kind durch Abtreibung zu opfern, weil jüdische Frauen, die schwanger wurden, sonsts gleich in ein $\mathrm{KZ}$ geschickt wurden. Die Familie verbrachte zwei Jahre in Theresienstadt, wo Frankls Vater verhungerte. Er war schon über 80 Jahre alt gewesen. Im Oktober wurden Frankl und seine Frau nach Auschwitz deportiert, und eine Woche danach auch seine hochgeliebte Mutter, die bei der Ankunft gleich vergast wurde. Tilly Frankl lebte bis zur Befreiung von Bergen-Belsen im April 1945, verstarb aber kurz danach. Frankl selbst verbrachte nur drei Tage in Auschwitz, wurde darauf weiter nach Dachau geschickt, wo er unter den Überlebenden war, als das Lager im April 1945 von amerikanischen Soldaten befreit wurde.

Wer den Titel „Viktor E. Frankl und der Holocaust" hört, denkt wohl in erster Linie an sein Buch "Ein Psychologe erlebt das Konzentrationslager", 
das sich in amerikanischer Übersetzung („Man’s Search for Meaning“) in Millionen Exemplaren verkauft hat. In Österreich wurde es kein Erfolg; die zweite Auflage wurde sogar makuliert. ${ }^{2}$ Ich werde in meinem Vortrag aber hauptsächlich nicht dieses Buch behandeln; dieses Thema ist besonders auf amerikanischem Boden schon ausreichend behandelt worden. Statt dessen werde ich mich mit anderen Büchern, in denen Frankl sich mit dem Holocaust befaßt, auseinandersetzen. Er hat eigentlich über das KZ-Buch hinaus kein anderes Buch über dieses Thema geschrieben; abgesehen vom „Unbewußten Gott", das die Religion behandelt, und der autobiographischen Skizze "Was nicht in meinen Büchern steht" von 1995, ist das Thema seiner Bücher die Psychotherapie. Er kehrte aber zu seinen Erlebnissen im $\mathrm{KZ}$ ständig wieder, teils in Beispielen für psychologische Erscheinungen, teils in direkten Bemerkungen über den Holocaust. In einem Interview im Jahre 1995, als er 90 Jahre alt war, sagte er: „You asked me earlier, Do I still think of these things? Not a day goes when I do not: ${ }^{\text {“3 }}$

Nachschlagewerke lassen uns in der Regel wissen, daß Frankl seine Theorien in den Konzentrationslagern entwickelte, so z. B. Encyclopaedia Judaica: „During this period he gained new insights into human nature, which he later developed into his philosophy and theory of logotherapy." Dies ist ein Mißverständnis, denn Frankl hatte seine Theorien bereits in den dreißiger Jahren formuliert. ${ }^{4}$ Er sagte, er sei „ein jüdischer Nervenarzt aus Wien“, „dessen Theorien in Auschwitz und Dachau getestet worden sind. "5 Wenn er "getestet" sagt, sollte man es buchstäblich verstehen. Andrerseits ist es aber leicht zu verstehen, wie dieses Mißverständnis entstanden ist, kommen doch Hinweise auf den Holocaust in den Büchern Frankls fast überall vor. Z. B. in einem Vortrag von 1977,42 Jahre nach der Befreiung, weist er auf 55 ziemlich kleinen Seiten fünfmal auf den Holocaust hin. ${ }^{6}$ Die Erlebnisse im KZ boten ihm das Material dar, an dem er seine Ideen überzeugend exemplifizieren konnte.

In den Jahren unmittelbar nach dem Krieg war Frankl sehr produktiv: „Ärztliche Seelsorge“ und „Ein Psychologe erlebt das Konzentrationslager" hat er schon 1945 diktiert. In den vierziger Jahren veröffentlichte er insgesamt acht Bücher. Viele von diesen basieren auf Vorlesungen, die er sowohl an der Universität als auch in eher populären Zusammenhängen hielt. Einige von den Vorlesungen, in denen Frankl sich mit dem Holocaust auseinandersezte, hielt er nur einige Monate nach der Befreiung. Eine zusätzliche, wahrscheinlich ziemlich unbekannte Quelle besteht aus Frankls Briefen an seinen Mitarbeiter Wilhelm Börner aus den Jahren 1945 bis 1949. Abgesehen vom Briefwechsel mit den Mitarbeitern Elisabeth Lukas und Joseph Fabry in den sechziger, siebziger und achziger Jahren sind seine Briefe nicht veröffentlicht 
worden. Der erste Brief an Börner ist auf den 3. Mai 1945, also weniger als eine Woche nach der Befreiung aus dem Lager Türkheim, einem Filiallager von Dachau, datiert. Er lautet: „Aus Konzentrationslager befreit, Gott sei Dank gesund, Mutter und Gattin verschleppt, ohne Nachricht. "7 Diese Briefe wurden 1996 in einem Festschrift für Juha Manninen, einen finnischen Philosophen, veröffentlicht.

Frankl glaubte zweifelsohne an Gott, und er war ein praktizierender Jude, jedenfalls von der KZ-Zeit bis seinem Tode. Ich halte es für wahrscheinlich, $\mathrm{da}$ er in den Jahren in den Konzentrationslagern ein Gläubiger wurde, obzwar er m. W. dies niemals offen sagte. In der „Ärztlichen Seelsorge " schreibt er aber von Gott: „An den wieder zu glauben, hat so mancher im Konzentrationslager und durch das Konzentrationslager gelernt. ${ }^{\text {" }}$ Es gibt viele Belege dafür, daß Frankl in seinen Büchern auf sich selbst in dritter Person hinweist. Z. B. heißt es just in der „Ärztlichen Seelsorge “ "Uns ist folgender Fall bekannt: [...]daß er ein noch unveröffentlichtes wissenschaftliches Buchmanuskript, das ihm im Konzentrationslager fortgenommen war, [...] rekonstruier-

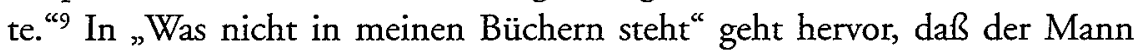
Frankl war und das Manuskript die „Ärztliche Seelsorge ${ }^{\prime 10}$ Und in „The Will to Meaning“ erzählt Frankl von einem Mann, der zusammen mit seiner jungen Frau in Auschwitz verhaftet wurde:

When they came there, he told me after his liberation, and were separated from each other, he suddenly felt a strong urge to implore her to survive "at any expense - you understand? At any cost..."

Auch in dieser Fall wird der Schleier in "Was nicht in meinen Büchern steht" gelüftet:

Als dann Männer und Frauen getrennt wurden, sagte ich ihr mit eindringlichen Worten, so daß sie auch wirklich verstehen konnte, was ich damit sagen wollte: „Tilly, um jeden Preis am Leben bleiben - verstehst Du, um jeden Preis! ${ }^{\alpha 12}$

Daher finde ich es wahrscheinlich, daß Frankl mit „so manchem“, der „im Konzentrationslager und durch das Konzentrationslager gelernt " hat, wieder an Gott zu glauben, in verschleierter Weise auf sich selbst hinweist.

Andererseits ist zu bemerken, daß in der vor der Deportation geschriebenen Erstfassung der „Ärztlichen Seelsorge“, die mir das Viktor-Frankl-Institut in Wien zugänglich machte, schon mehrere positive Äußerungen über den Gottesglauben enthalten sind [S. I7, 21-22, I62 Anm. z. S. 38].

In einem Vortrag im Februar 1947 wandte Frankl das Bubersche Bild von der Ich-Du-Beziehung folgendermaßen an: 
Und ich weiß nicht, ob es zum Beispiel einem Menschen, der einmal, sagen wir in einem Konzentrationslager war, im Graben gestanden ist und zu Gott gesprochen hat, ob es diesem Menschen jemals wieder möglich ist, auf einem Katheder zu stehen, sagen wir: in diesem Hörsaal, und von Gott zu sprechen als von demselben, $z u$ dem er damals im Graben gesprochen hat... ${ }^{13}$

(Höchstwahrscheinlich hat sich hier ein Druckfehler eingeschlichen, sogar zweimal: „im Graben“ sollte wohl „im Grabe“heißen. Zwar hat Frankl im KZ Gräben gegraben, aber das geht aus dem Zusammenhang nicht hervor.) Auch Martin Buber hat den Unterschied zwischen von Gott sprechen und zu ihm sprechen hervorgehoben. ${ }^{14}$ Frankl hat in diesem Zusammenhang nicht auf Buber hingewiesen; er war aber mit Bubers Denken vertraut. Er betrachtete das von Gott Sprechen als unvereinbar mit dem $z u$ Gott Sprechen: wer noch imstande sei, von Gott zu sprechen, könne möglicherweise auch $z u$ ihm sprechen, aber für den, der in seiner äußersten Not $z u$ ihm gesprochen hat wie ein Überlebender des Holocaust - seien ein Gott, $z u$ dem man spricht, und ein Gott, von dem man spricht, verschiedene Begriffe.

Der Gottesglaube ist im jüdischen Denken nach dem Holocaust in der Regel problematisiert worden. Wenn Frankl feststellt, daß „so mancher im Konzentrationslager und durch das Konzentrationslager gelernt " habe, wieder an Gott zu glauben, scheint dies etwas polemisch gemeint zu sein. In einem Vortrag in Dallas 1985 kritisierte er das berühmte Buch von Richard Rubenstein, „After Auschwitz", nach dem Gott für die meisten ehemaligen KZ-Häftlinge tot sei. Laut Frankl verhält es sich umgekehrt, und betreffend Rubenstein bemerkte er: „Er war ja nicht in Auschwitz." Wie Frankl es sieht,

ist der Glaube an Gott entweder ein bedingungsloser, oder es handelt sich nicht um einen Glauben an Gott. Ist er bedingungslos, so wird er auch standhalten, wenn sechs Millionen dem Holokaust zum Opfer gefallen sind, und ist er nicht bedingungslos, so wird er - um mich der Argumentation von Dostojewski zu bedienen - angesichts eines einzigen unschuldigen Kindes, das im Sterben liegt, aufgeben; denn handeln können wir mit Gott nicht, wir können nicht sagen: Bis sechstausend oder von mir aus einer Million Holokaust-Opfer erhalte ich meinen Glauben an dich aufrecht: aber von einer Million aufwärts ist nichts zu machen, und - es tut mir leid - ich muß meinen Glauben an dich aufkündigen. ${ }^{15}$

Ich bin in erster Linie Exeget und interessiere mich deswegen auch für die Bibelzitate in Frankls Büchern. Er führt 46 Stellen in der hebräischen Bibel an. 16 von diesen Zitaten sind auf den Psalter bezogen; er hat ihn sehr geliebt. 
Zum Abschluß werde ich ein Zitat, das im KZ-Buch, „Ein Psychologe erlebt das Konzentrationslager", enthalten ist, erörtern. Frankl kleidet seine Stimmungen unmittelbar nach der Befreiung aus dem KZ im April I945 in u. a. folgende Worte:

Dann gehst du eines Tages, ein paar Tage nach der Befreiung, übers freie Feld [...] du hörst in dir nur einen Satz, und immer wieder denselben Satz: „Aus der Enge rief ich den Herrn, und er antwortete mir im freien Raum. ${ }^{\text {"16 }}$

Der Satz ist aus dem Ir8 Psalm, Vers 5. Dieser Psalm wird als ein Hallel-Psalm in der Pesach-Feier rezitiert, und zwar gegen Ende der Feier, nach der vollzogenen Befreiung aus Ägypten. Der Wortlaut des Zitats geht wahrscheinlich auf die deutsche Übersetzung des Gebetbuches durch den reformjüdischen Rabbiner Isaac Noah Mannheimer zurück, wo es heißt: „In der Enge rief ich Gott, und Gott antwortete mir im freien Raum. "Dieses Gebetbuch habe ich unter Frankls Nachlaß gefunden. Gewöhnlich hat Frankl in seinen Büchern von den vierziger Jahren die Übersetzung von Leopold Zunz zitiert. Daß das Zitat nicht wörtlich mit Mannheimer übereinstimmt deutet darauf hin, daß Frankl den Vers auswendig zitiert hat. So hat er in der Regel nicht gemacht; abgesehen von unerheblichen Ausweichungen stimmen seine Zitate wörtlich mit Zunz überein. Dies macht es wahrscheinlich, daß er den Vers bei der Pesach-Feier gelernt hat. Hierzu sollten noch die Verse I7, I8 und 21 des Psalms verglichen werden (im Wortlaut der Übersetzung von Mannheimer):

Ich sterbe nicht, nein, ich lebe und erzähle die Thaten Gottes.

Gezüchtigt hat mich Gott, aber nicht dem Tode hingegeben.

Ich danke dir, Gott, daß Du mich hast erhöret, und warst mein Heil.

Es scheint mir also, daß Frankl die Befreiung aus dem Konzentrationslager und sein Überleben des Holocaust als seinen Auszug aus Ägypten sah, und dies in die Worte des II8. Psalms kleidete.

Im Abschnitt „Zur Psychologie des Konzentrationslagers“ in der „Ärztlichen Seelsorge“, schreibt Frankl vom Überlebenden: „Nunmehr beherrscht ihn das köstliche Gefühl, nach all dem, was er erlebt und erlitten, nichts mehr auf der ganzen Welt fürchten zu müssen - außer vielleicht seinen Gott. “ Dieselbe Äußerung steht auch im KZ-Buch, doch ohne das Wort „vielleicht“. In der siebenten Auflage der „Ärztlichen Seelsorge " 1966 ist es auch weggelassen worden. ${ }^{17}$ Es fragt sich, ob die Überlebenden in der Regel von diesem köstlichen Gefühl beherrscht waren. Waren sie nicht eher ängstliche Menschen, deren Leben dadurch wesentlich erschwert, ja sogar unerträglich wurde, daß sie nach dem erlebten fast alles auf der Welt fürchten mußten? Daher scheint es mir, daß Frankl kein typischer Überlebender war. 


\section{AnMerkungen}

I. Frankl I995b, 31; Beller 1989, 44 .

2. Frankl 19956,$83 ;$ 1997b.

3. Scully $1995,43$.

4. Frankl I998, 3I-35 (ein ursprünglich I938 veröffentlichter Artikel).

5. Fleckenstein 1975 , II2.

6. Frankl 1996, 32, 44, 66, 70.

7. Gimpl 1996,39 r.

8. Frankl I982, II3.

9. Frankl 1982, 103.

Io. Frankl 1995 b, $75-77$.

II. Frankl I988, 63-64.

I2. Frankl $x 9956,68$.

I3. Frankl 1997a, 67; Kursivdruck von Frankl).

14. Buber 1954, 76 .

15. Frankl 199I, II6.

16. Frankl 1995a, I43.

I7. Frankl I946 82; 1966, II3; I995a, I48.

\section{Quellenverzeichnis}

Beller, Steven. 1989. Vienna and the Jews $7867-1938$. A cultural history. Cambridge.

Buber, Martin. I954. Die Schriften über das dialogische Prinzip. Ich und Du / Zwiesprache. Die Frage an den Einzelnen. Elemente des Zwischenmenschlichen. Mit einem Nachwort. Heidelberg.

Fabry, Joseph \& Lukas, Elisabeth. 1995. Auf den Spuren des Logos. Briefwechsel mit Viktor E. Frankl. Mit einem Epilog von Eugen Thurnher. Berlin.

Fleckenstein, Karl-Heinz. 1975. Am Fenster der Welt. Im Gespräch mit: Heinz Rühmann, Robert Jungk, Ota Sik, Leo Schürmann, Léopold Senghor, Thor Heyerdahl, Kurt Waldheim, Viktor E. Frankl, Luise Rinser, Gundula Janowitz, Eddi Merckx, Rudolf Kirchschlüger, Franz König, Wernher von Braun. München.

Frankl, Viktor E. 1946. Ärtliche Seelsorge. Wien.

Frankl, Viktor E. 1982. Ärztliche Seelsorge. Grundlagen der Logotherapie und Existenzanalyse. Zehnte, ergänzte Auflage. Wien.

Frankl, Viktor E. 1988. The Will to Meaning. Foundations and Applications of Logotherapy. Expanded edition. New York.

Frankl, Viktor E. 1991. Der unbewußte Gott. Psychotherapie und Religion. 8. Auflage. München.

Frankl, Viktor E. 1995(a). ...trotzdern Ja zum Leben sagen. Ein Psychologe erlebt das Konzentrationslager. Vorwort von Hans Weigel. 7. Auflage. München.

Frankl, Viktor E. 1995(b). Was nicht in meinen Büchern steht. Lebenserinnerungen. 2. Auflage. München.

Frankl, Viktor E. 1996. Die Sinnfrage in der Psychotherapie. Mit einem Vorwort von Franz Kreuzer. Mit 7 Abbildungen. Erweiterte Neuausgabe. 6. Auflage. München. 
Frankl, Viktor E. 1997(a) Der Wille zum Sinn. Ausgewählte Vorträge über Logotherapie. Mit einem Beitrag von Elisabeth S. Lukas. Mit I6 Abbildungen. Erweiterte Taschenbuchausgabe. 4. Auflage. München.

Frankl, Viktor E. I997(b). 70 Jahre miterlebte „Evolution der Psychotherapie“. Vortrag am Weltkongreß Evolution of Psychotherapy, Hamburg 1994. Cassette.

Frankl, Viktor E. 1998. Logotherapie und Existenzanalyse. Texte aus sechs Jahrzehnten. 3., neu ausgestattete Auflage. Weinheim.

Gimpl, Georg (Hrsg.) 1996. Ego und Alterego. Wilhelm Bolin und Friedrich Jodl im Kampf um die Aufklärung. Festschrift für Juha Manninen. Frankfurt am Main.

Scully, Matthew. x995. "Viktor Frankl at Ninety: An Interview." First Things 52, 39-43.

\section{SAMMANFATTNING}

Viktor Frankl föddes i en judisk familj i Wien 1905. Han kom att stanna i staden till 1942 , då han deporterades till ett koncentrationsläger. Hans föräldrar, hustru, bror och svägerska dog under Förintelsen; själv överlevde han och återvände till Wien. Frankl är mest känd som författaren till Livet måste ha en mening (Ein Psychologe erlebt das Konzentrationslager, eng. övers.: Man's Search for Meaning), där han beskriver koncentrationslägret ur psykologens synvinkel. Denna artikel behandlar emellertid hans övriga verk, vilka inte primärt behandlar Förintelsen. Frankl utvecklade sina viktigaste tankar om livets mening redan under 1930-talet och brukade säga att de testades $i$ koncentrationslägret. Som observant jude - troligen stärktes hans övertygelse av Förintelsen - poängterade han att Förintelsen snarare lärde sina offer att tro på Gud än fick dem att överge denna tro. 